\title{
Comparative Approach to Interaction of Zinc Dication with Theobromine and Theophilline-A DFT Treatment
}

\section{Lemi Türker}

Department of Chemistry, Middle East Technical University, Üniversiteler, Eskişehir Yolu No: 1, 06800 Çankaya/Ankara, Turkey; e-mail: 1turker@gmail.com; 1turker@metu.edu.tr

\begin{abstract}
Two isomeric methylxanthines, theobromine and theophilline, and their $\mathrm{Zn}^{+2}$ containing composites are considered within the restrictions of density functional theory (B3LYP/ 6$31++G(d, p))$. Certain quantum chemical, thermodynamic and spectral data have been harvested, compared and interpreted. The results revealed that theophilline $+\mathrm{Zn}^{+2}$ system is thermodynamically more exothermic, more favorable and electronically stable compared to the analogous system, theobromine $+\mathrm{Zn}^{+2}$.
\end{abstract}

\section{Introduction}

Theobromine, theophilline and caffeine are three important methylxanthines of which theophylline is important as a therapeutic agent in the treatment of asthma. Theobromine is 3,7-dimethylxanthine and theophilline, its isomer, is 1,3-dimethylxanthine. Several mechanisms have been proposed for the action of the methylxanthines. In vitro experiments it has been shown that they inhibit the enzyme called phosphodiesterase [1].

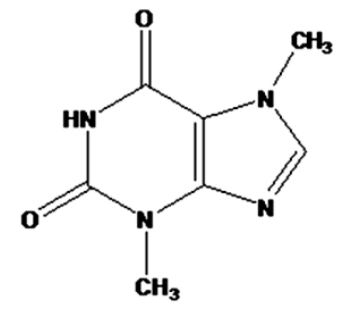

Theobromine

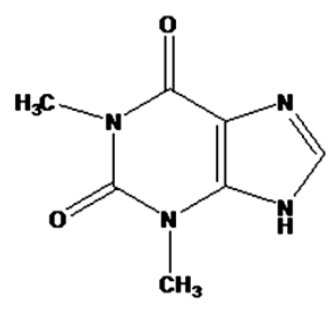

Theophilline

Received: January 5, 2021; Accepted: February 13, 2021

Keywords and phrases: theobromine, theophilline, methylxanthines, zinc dication, density functional.

Copyright (C) 2021 Lemi Türker. This is an open access article distributed under the Creative Commons Attribution License, which permits unrestricted use, distribution, and reproduction in any medium, provided the original work is properly cited. 
Various research has been done on various properties and actions of methylxanthines quite recently [2-5].

Theobromine, formerly known as xantheose, is a bitter alkaloid of the cacao plant, with the chemical formula $\mathrm{C}_{7} \mathrm{H}_{8} \mathrm{~N}_{4} \mathrm{O}_{2}$. It is found in chocolate, as well as in a number of other foods, including the leaves of the tea plant, and the kola nut. Theobromine, which is found in higher amounts than caffeine, seems to be behind several effects attributed to cocoa intake. The main mechanisms of action are inhibition of phosphodiesterases and blockade of adenosine receptors. Therefore, theobromine deserves attention as one of the most attractive molecules in cocoa. Theobromine is used as a vasodilator (a blood vessel widener), as an aid in urination, and as a heart stimulant. Although the theobromine content in chocolate is small enough to be safely consumed by humans, it is reported that animals such as dogs metabolize theobromine more slowly and may succumb to theobromine poisoning.

On the other hand, zinc is an essential element in the metabolic processes of living organisms. It is the second most abundant transition or post-transition metal which is transported by proteins (macroglobulin, transferrin, and albumin) and stored in a protein (thionein), and bound to proteins that is generally bound to histidines, carboxylatecontaining residues, and cysteines. It may coordinate a substrate molecule and activate it for the required reaction. Also, zinc acts as a Lewis acid; i.e., it accepts lone pairs by donor groups; its Lewis acid properties are primarily important when it acts as catalyst [6]. Zinc metabolism is tissue and organ specific. The intracellular concentration of unbound "free" $\mathrm{Zn}^{2+}$ is extremely low. Homeostatic system of proteins regulates cellular $\mathrm{Zn}^{2+}$ distribution and perhaps controls a hierarchy of zinc-dependent functions. Eukaryotic zinc transporters have a major, but still only partly defined, regulatory role [7].

It has been established that caffeine affects zinc absorption and $\mathrm{Zn}$ concentration in rat tissue [8]. Interaction of metal ions with caffeine and theophylline was investigated by Nafisi et al., [9]. Metal(II) complexes with theophylline [10] and the controlled release of theophylline from metal-drug complexes in vitro were reported [11].

In the present study, isomeric methylxanthines, theobromine and theophilline, are considered within the realm of density functional theory (DFT).

\section{Method of Calculation}

In the present study, the initial structural optimizations of all the structures leading to 
energy minima have been achieved by using MM2 method followed by semiempirical PM3 self-consistent fields molecular orbital (SCF MO) method $[12,13]$ at the restricted level $[14,15]$. The subsequent optimizations were achieved at Hartree-Fock level using various basis sets hierarchically. Then, the structural optimizations were managed within the framework of density functional theory (DFT) $[16,17]$ at the levels of and B3LYP/6$31++G(d, p)[15,18]$. The exchange term of B3LYP consists of hybrid Hartree-Fock and local spin density (LSD) exchange functions with Becke's gradient correlation to LSD exchange $[17,19]$. The correlation term of B3LYP consists of the Vosko, Wilk, Nusair (VWN3) local correlation functional [20] and Lee, Yang, Parr (LYP) correlation correction functional [21]. Additionally, the vibrational analyses have been done. The total electronic energies are corrected for the zero point vibrational energy (ZPE). The normal mode analysis for each structure yielded no imaginary frequencies for the $3 \mathrm{~N}-6$ vibrational degrees of freedom, where $N$ is the number of atoms in the system which indicates that the structure of each molecule corresponds to at least a local minimum on the potential energy surface. All these calculations were done by using the Spartan 06 package program [22].

\section{Results and Discussion}

Figure 1 shows the zinc dication composites of the isomeric methylxanthines, theobromine and theophilline. These systems have the zinc dication occupying different locations in space and also due to the different positions of the methyl groups, the direction of the dipole moment vectors is different. The values of dipole moment vectors for zinc dication having theobromine and theophilline systems are 15.18 and 16.54 debye, respectively.

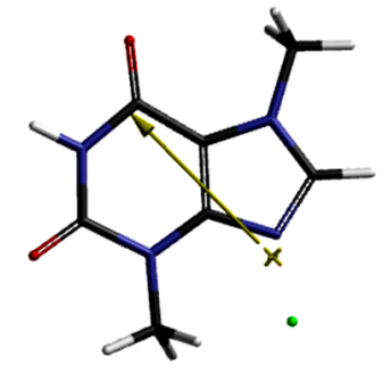

Theobromine $+\mathrm{Zn}^{+2}$

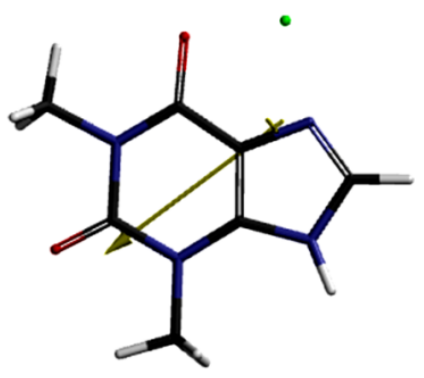

Theophilline $+\mathrm{Zn}^{+2}$

Figure 1. Optimized structures of the systems considered presently. 
Note that in the case of theophilline, the zinc cation resides next to the carbonyl oxygen atom as well as next to the $\mathrm{sp}^{2}$-hybridized nitrogen atom. Therefore, some sort of interaction of zinc cation with lone-pairs of those heteroatoms is more probable as compared to theobromine counterpart.

Figure 2 shows the electrostatic potential (ESP) charges on the atoms of the systems considered. Note that the ESP charges are obtained by the program based on a numerical method that generates charges that reproduce the electrostatic potential field from the entire wavefunction [22]. The data reveal that in the theobromine case the zinc cation has 1.298 esu of charge which is less than the charge of the respective atom in the theophilline case which is 1.515 esu. Namely, more electron population has been transferred from theobromine to the zinc cation as compared to the theophilline case.
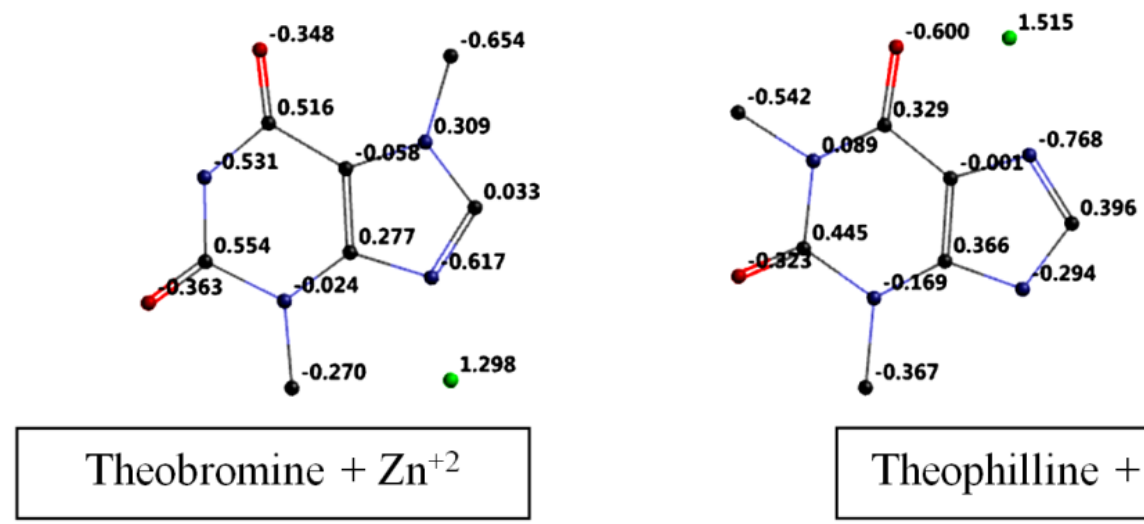

$$
\text { Theophilline }+\mathrm{Zn}^{+2}
$$

Figure 2. The ESP charges on the atoms of the structures considered (hydrogens omitted).

Figure 3 shows the electrostatic potential maps of the systems considered. In the figure the blue/bluish and red/reddish regions show the positive and negative potential regions, respectively. As seen in the figure in the presence of the zinc cation all parts of the organic components are in the positive potential field.

According to the heat of formation and Gibbs free energy of formation data presented in Table 1 the systems are exothermic and thermally favorable. The values for theophilline $+\mathrm{Zn}^{+2}$ system exceed (absolutely) the theobrommine $+\mathrm{Zn}^{+2}$. 


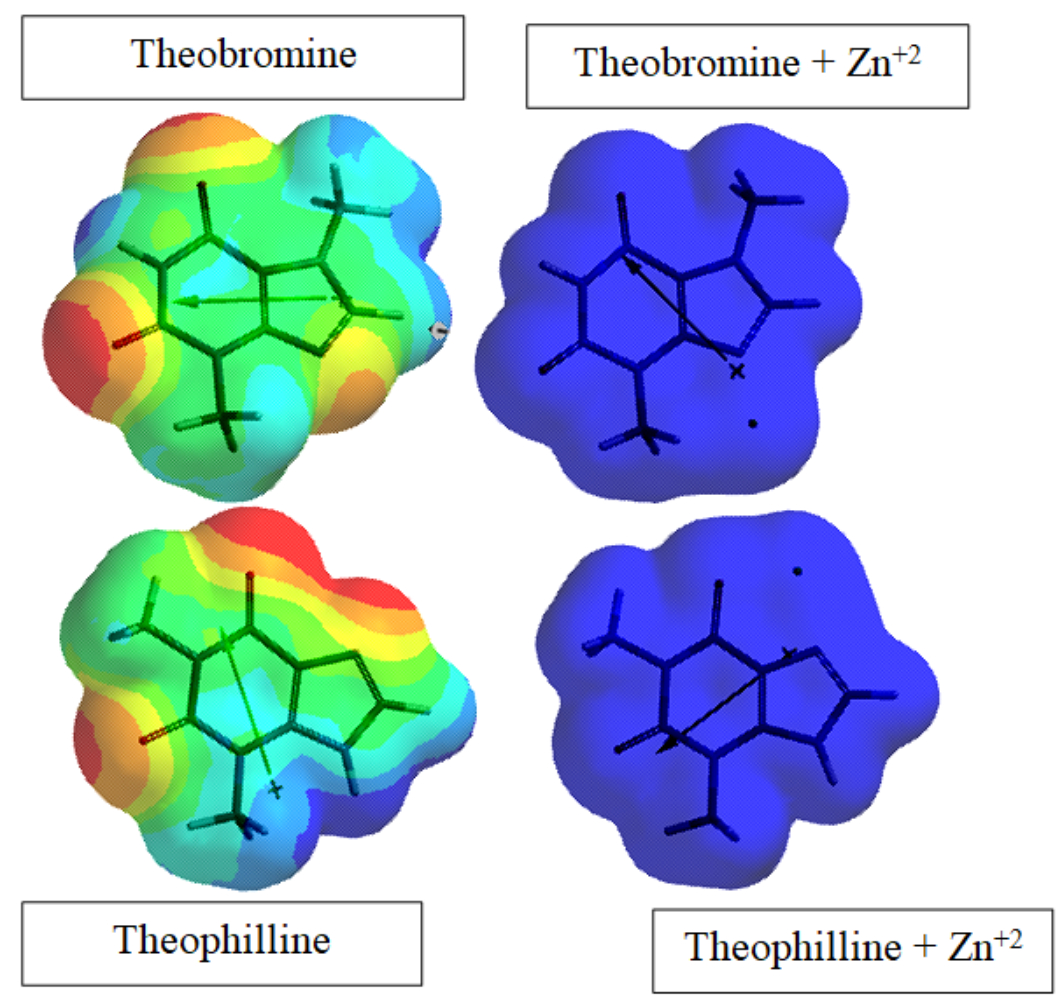

Figure 3. Electrostatic potential maps of the present systems.

Table 1. Some thermodynamic properties of the systems considered.

\begin{tabular}{lccc}
\hline System & $\mathbf{H}^{\mathbf{o}}$ & $\mathbf{S}^{\mathbf{o}}\left(\mathbf{J} / \mathbf{m o l}^{\mathbf{0}}\right)$ & $\mathbf{G}^{\mathbf{o}}$ \\
\hline Theobromine & -1682786.278 & 409.39 & -1682908.339 \\
Theophilline & -1682739.194 & 408.38 & -1682860.956 \\
Theobromine $+\mathrm{Zn}^{+2}$ & -6352075.707 & 434.40 & -6352205.224 \\
Theophilline $+\mathrm{Zn}^{+2}$ & -6352256.606 & 435.80 & -6352386.543 \\
\hline
\end{tabular}

Energies in $\mathrm{kJ} / \mathrm{mol}$.

These zinc containing systems are electronically stable as well, as seen in Table 2, where $\mathrm{E}, \mathrm{ZPE}$ and $\mathrm{E}_{\mathrm{C}}$ stand for the total electronic energy, zero point vibrational energy and the corrected total electronic energy, respectively. Again theophilline $+\mathrm{Zn}^{+2}$ system is more stable than its counterpart. The underlying reason for it could be the existing some lone-pair-cation interaction as mentioned in previous paragraphs. 
Table 2. Some energies of the systems considered.

\begin{tabular}{lccc}
\hline System & $\mathbf{E}$ & $\mathbf{Z P E}$ & $\mathbf{E}_{\mathbf{C}}$ \\
\hline Theobromine $+\mathrm{Zn}^{+2}$ & -6352469.24 & 420.94 & -6352048.30 \\
Theophilline $+\mathrm{Zn}^{+2}$ & -6352655.63 & 426.01 & -6352229.62 \\
\hline
\end{tabular}

Energies in $\mathrm{kJ} / \mathrm{mol}$.

Figure 4 depicts the IR spectra of these zinc dication containing systems compared to
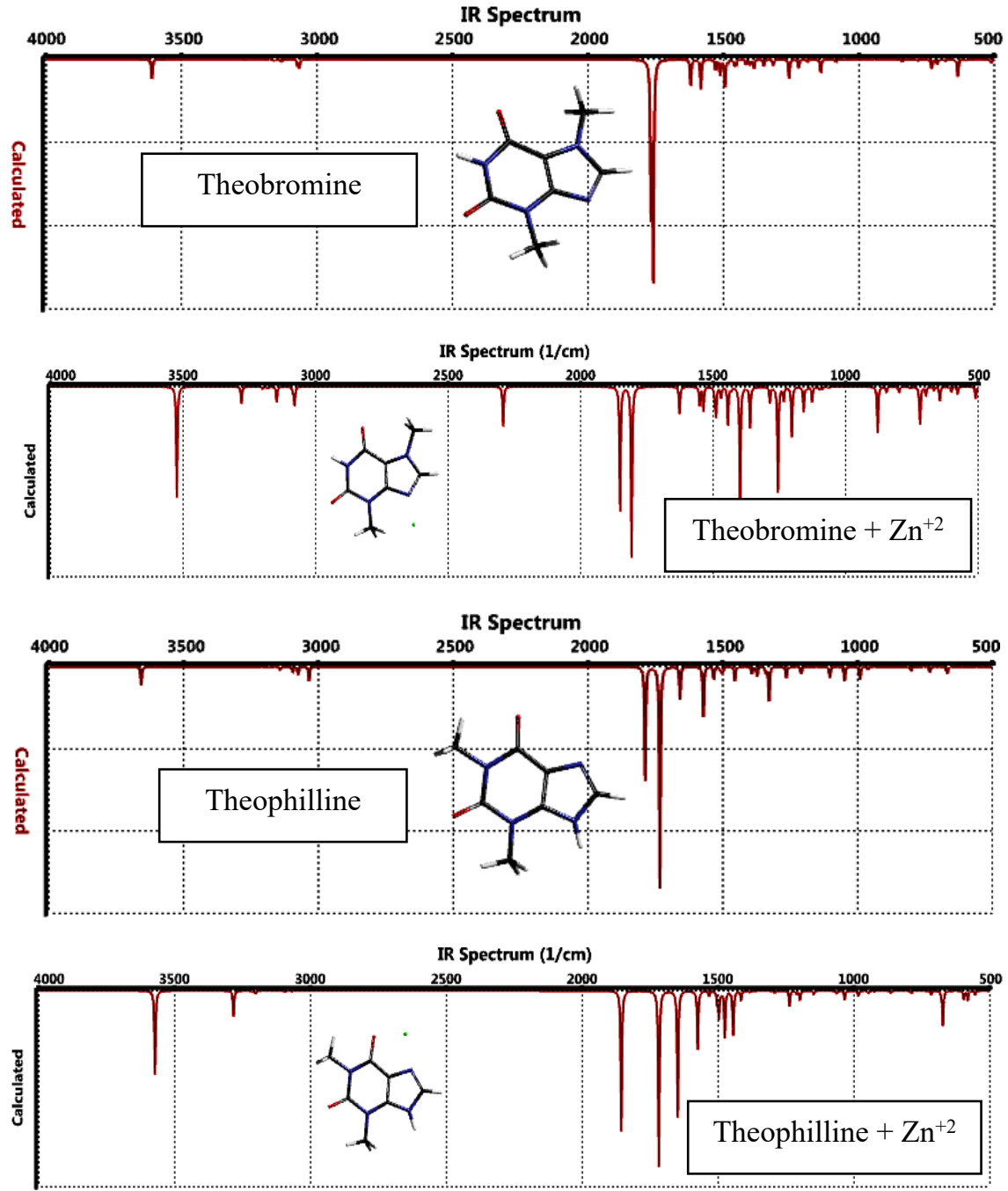

Figure 4. Calculated IR spectra of the systems. 
the spectra of their organic components. The first noticeable difference is that the presence of zinc cation makes $\mathrm{N}-\mathrm{H}$ vibration $\left(3524 \mathrm{~cm}^{-1}\right.$ theobromine $+\mathrm{Zn}^{+2}$ and 3572 $\mathrm{cm}^{-1}$ theophilline $+\mathrm{Zn}^{+2}$ ) band to be more accentuated. The carbonyl stretchings are better separated in the presence of the zinc cation. The $\mathrm{C}-\mathrm{H}$ stretching of methyl hydrogens are also affected by the zinc cation.

Figure 5 shows some of the molecular orbital energy levels of the systems considered. As seen there, the presence of $\mathrm{Zn}^{+2}$ highly lowers the molecular orbitals as compared to theobromine and theophilline themselves.
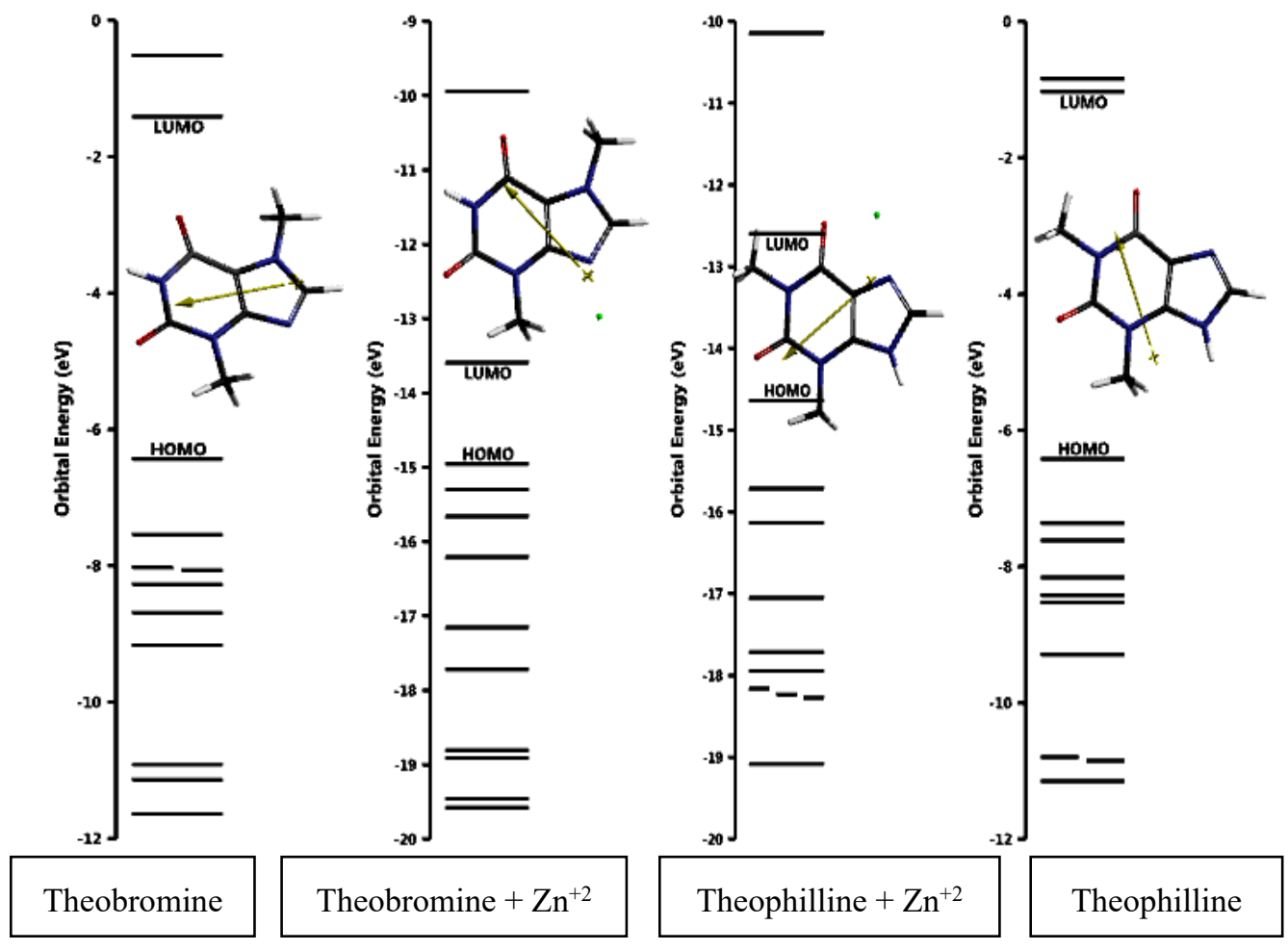

Figure 5. Some of the molecular orbital energy levels of the systems considered.

Table 3 lists the HOMO, LUMO energies and the interfrontier molecular orbital energy gap values $(\Delta \varepsilon)$. The HOMO order is theobromine $+\mathrm{Zn}^{+2}<$ theophilline $+\mathrm{Zn}^{+2}<$ theobromine $<$ theophilline. The same order holds for the LUMO energies. Whereas, $\Delta \varepsilon$ values follow the order of theophilline $>$ theobromine $>$ theophilline $+\mathrm{Zn}^{+2}>$ theobromine $+\mathrm{Zn}^{+2}$. The unequal energy lowering of the HOMO and LUMO energies in the presence of $\mathrm{Zn}^{+2}$ results in $\Delta \varepsilon$ that theophilline $+\mathrm{Zn}^{+2}>$ theobromine $+\mathrm{Zn}^{+2}$ order happens. 
Table 3. The HOMO, LUMO energies and $\Delta \varepsilon$ values of the systems considered.

\begin{tabular}{lccc}
\hline System & HOMO & LUMO & $\Delta \boldsymbol{\varepsilon}$ \\
\hline Theobromine & -621.20 & -136.22 & 484.98 \\
Theophilline & -619.43 & -99.84 & 519.59 \\
Theobromine $+\mathrm{Zn}^{+2}$ & -1443.12 & -1311.32 & 131.80 \\
Theophilline $+\mathrm{Zn}^{+2}$ & -1412.46 & -1215.23 & 197.23 \\
\hline
\end{tabular}

Energies in $\mathrm{kJ} / \mathrm{mol}$.

Figure 6 displays the time-dependent UV-VIS spectra of the systems presently considered. The calculated spectra of theobromine and theophilline absorb in the ultraviolet region. Whereas, as seen in the figure, the presence of $\mathrm{Zn}^{+2}$ causes appearance of new absorptions and a bathochromic shift to visible region occurs as compared to the spectra of the parent systems. The zinc dication in these systems acting as if it were an electron withdrawing substituent, thus lowering the HOMO and LUMO energy levels at unequal extents. Because of that the HOMO-LUMO energy gap $(\Delta \varepsilon)$ narrows, thus a bathochromic shift occurs in the spectra.

Figure 7 shows the LUMO maps of the systems of present consideration. A LUMO map displays the absolute value of the LUMO on the electron density surface. The blue color stands for the maximum value of the LUMO and the color red, the minimum value and the yellow-green regions are in between. Hence, a nucleophile attacks on the atom having the blue color. As seen in the figure, theobromine is relatively less susceptible to nucleophilic attack. On the other hand, in the zinc containing systems, theophilline moiety is more susceptible to nucleophiles than the theobromine. 

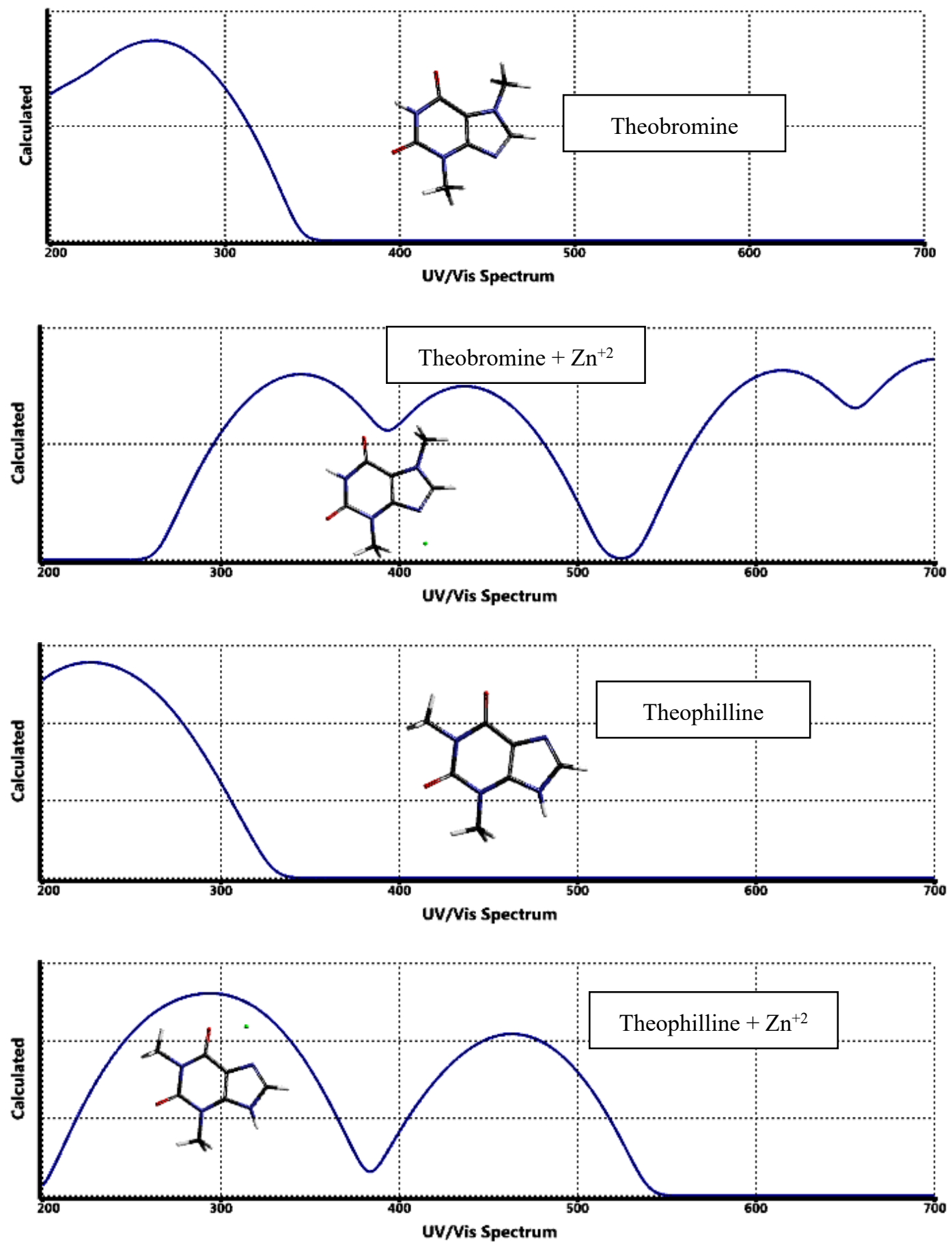

Figure 6. Time dependent UV-VIS spectra of the systems of present concern. 

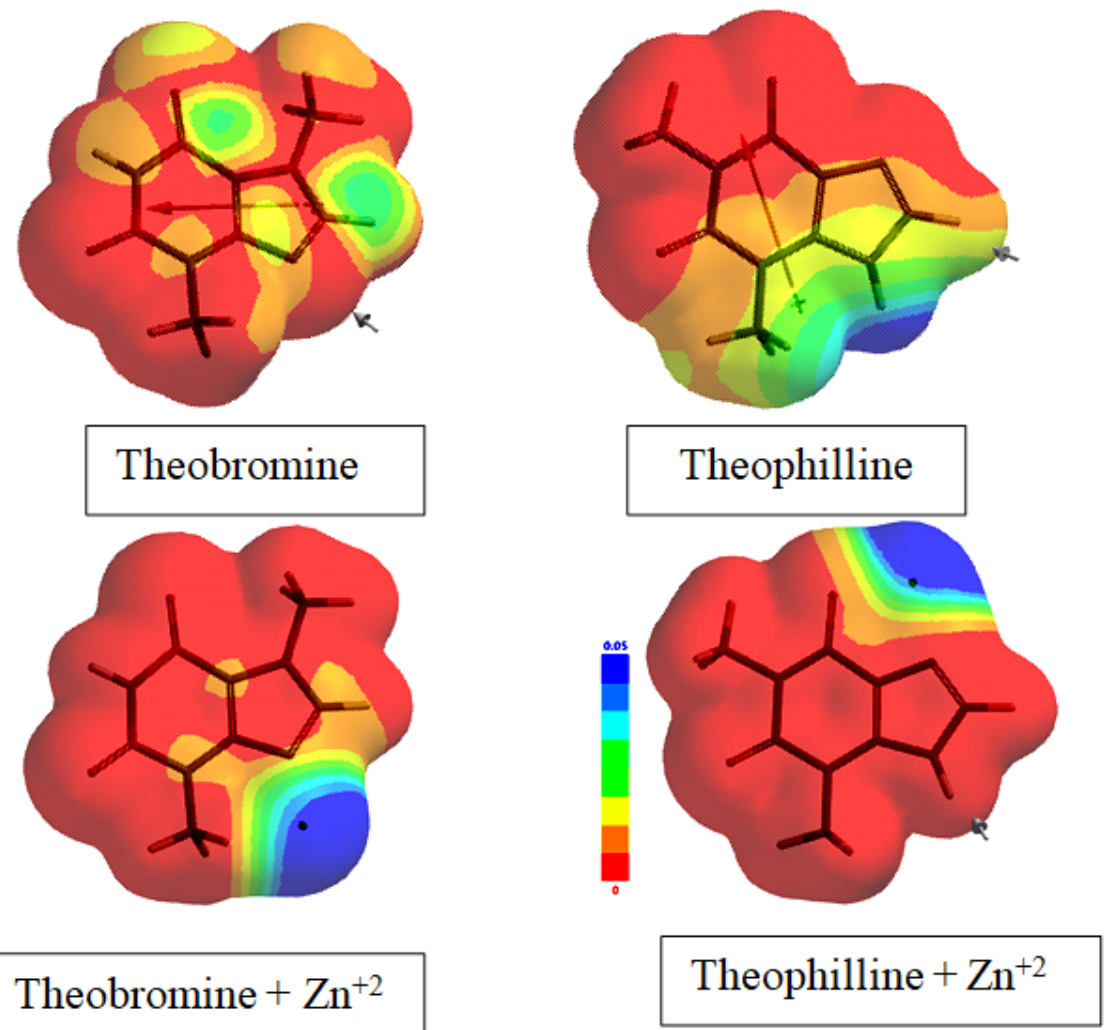

Figure 7. The LUMO maps of the systems considered.

\section{Conclusion}

The present study has revealed that theobromine and theophilline interacts with zinc dication in such a way that some electron population has been transferred to the zinc cation. This effect is more pronounced in the case of theobromine. However, thephilline $+\mathrm{Zn}^{+2}$ system is thermally and electronically more favorable and stable. This might be not only any charge-charge interaction between the organic and inorganic components but probably in the theophilline case some better complexation with $\mathrm{Zn}^{+2}$ occurs because the location of $\mathrm{Zn}^{+2}$ in that case is very suitable for zinc cation to interact with the lone-pairs of both the carbonyl oxygen atom and the $\mathrm{sp}^{2}$ hybridized nitrogen atom. However, in living organisms $\mathrm{Zn}$ dication forms many complexes (mostly aquated) with various ligands. Therefore, various competitive reactions are to be taken in to account to visualize the real effect of these dimethylxathines on the zinc metabolism. 


\section{References}

[1] H.A. Boushey and M.J. Holtzman, Bronchodilators and other agents used in the treatment of asthema, in Basic and Clinical Pharmacology, B.G. Katzung (Ed.), Los Altos, California: Lange, Medical Pub., 1984.

[2] J.P. Monteiro, M.G. Alves, P.F. Oliveira and B.M. Silva, Structure-bioactivity relationships of methylxanthines: Trying to make sense of all the promises and the drawbacks, Molecules 21(8) (2016), 974. https://doi.org/10.3390/molecules21080974

[3] R. Franco, A. Oñatibia-Astibia and E. Martínez-Pinilla, Health benefits of methylxanthines in cacao and chocolate, Nutrients 5 (2013), 4159-4173. https://doi.org/10.3390/nu5104159

[4] C.I.A.V. Santos, M.L. Ramos, L.L.G. Justino, H.D. Burrows, A.J.M. Valente, M.A. Esteso, D.G. Leaist and A.F.C. Ribeiro, Effect of $\mathrm{pH}$ in the structure and mass transport by diffusion of theophylline, J. Chem. Thermodyn. 110 (2017), 162-170. https://doi.org/10.1016/j.jct.2017.02.019

[5] P.J. Barnes, Pulmonary perspectives. Theophylline, Am. J. Respir. Crit. Care Med. 188 (2013), 901-906. https://doi.org/10.1164/rccm.201302-0388PP

[6] I. Bertini, C. Luchinat and R. Monnanni, Zinc enzymes, Journal of Chemical Education 62(11) (1985), 924-927. https://doi.org/10.1021/ed062p924

[7] K.M. Hambidge and N.F. Krebs, Zinc in the Fetus and Neonate, in Fetal and Neonatal Physiology (Fifth Edition), R.A. Polin, S.H. Abman, W.W. Fox, S.H. Abman, W.E. Benitz, (Eds.), vol. 1, 342-347, Philadelphia, PA, USA: Elsevier Saunders, 2004. https://doi.org/10.1016/B978-0-7216-9654-6.50038-2

[8] M.J. Rossowska and T. Nakamoto, Effect of caffeine on zinc absorption and Zn concentration in rat tissue, British Journal of Nutrition 64(2) (1990), 553-559. https://doi.org/10.1079/BJN19900055

[9] S. Nafisi, A.S. Sadjadi, S.S. Zadeh and M. Damerchelli, Interaction of metal ions with caffeine and theophylline: Stability and structural features, Journal of Biomolecular Structure \& Dynamics 21(2) (2003), 289-296.

https://doi.org/10.1080/07391102.2003.10506924

[10] M. Gacki, K. Kafarska, A. Pietrzak, I. Korona-Glowniak and W.M. Wolf, Synthesis, characterization, crystal structure and biological activity of metal(II) complexes with theophylline, J. Saudi Chem. Soc. 23 (2019), 346-354.

https://doi.org/10.1016/j.jscs.2018.08.006

[11] H. Wang, T-L. Hu, R-M. Wen, Q. Wang and X-H. Bu, In vitro controlled release of 
theophylline from metal-drug complexes, J. Mater. Chem. B 1 (2013), 3879-3882. https://doi.org/10.1039/C3TB20633E

[12] J.J.P. Stewart, Optimization of parameters for semiempirical methods I. Method, $J$. Comput. Chem. 10 (1989), 209-220. https://doi.org/10.1002/jcc.540100208

[13] J.J.P. Stewart, Optimization of parameters for semi empirical methods II. Application, $J$. Comput. Chem. 10 (1989), 221-264. https://doi.org/10.1002/jcc.540100209

[14] A.R. Leach, Molecular Modeling, Essex: Longman, 1997.

[15] P. Fletcher, Practical Methods of Optimization, New York: Wiley, 1990.

[16] W. Kohn and L. Sham, Self-consistent equations including exchange and correlation effects, J. Phys. Rev.140 (1965), 1133-1138. https://doi.org/10.1103/PhysRev.140.A1133

[17] R.G. Parr and W. Yang, Density Functional Theory of Atoms and Molecules, London: Oxford University Press, 1989.

[18] C.J. Cramer, Essentials of Computational Chemistry, Chichester, West Sussex: Wiley, 2004.

[19] A.D. Becke, Density-functional exchange-energy approximation with correct asymptotic behavior, Phys. Rev. A 38 (1988), 3098-3100. https://doi.org/10.1103/PhysRevA.38.3098

[20] S.H. Vosko, L. Wilk and M. Nusair, Accurate spin-dependent electron liquid correlation energies for local spin density calculations: a critical analysis, Can. J. Phys. 58 (1980), 1200-1211. https://doi.org/10.1139/p80-159

[21] C. Lee, W. Yang and R.G. Parr, Development of the Colle-Salvetti correlation-energy formula into a functional of the electron density, Phys. Rev. B 37 (1988), 785-789. https://doi.org/10.1103/PhysRevB.37.785

[22] SPARTAN 06, Wavefunction Inc., Irvine CA, USA, 2006. 